\title{
Research on the Marketing Strategy of Small Leisure Food Enterprises under O2O Model Driven
}

\author{
Qian Bai \\ School of Management, Yulin University, China, 719000 \\ 996969980@qq.com
}

Keywords: O2O; Marketing Strategy, Small Leisure Food Enterprises; 4P Theory

\begin{abstract}
With the development of information technology and network technology, accompanied by a large number of leisure food enterprises into the industry competition, how to enhance the competitiveness of enterprises is to think about the topic. This article takes small and medium-sized leisure food enterprises of our country are mainly research object, analysis of the driving effects of $\mathrm{O} 2 \mathrm{O}$ mode on leisure food marketing, the marketing situation, using the theory of 4P from the product, price, channel, promotion four aspects to develop marketing strategies more scientific and reasonable, and suggestions from the clear positioning, reasonable pricing online and offline, full channel integration, all-round promotion and other aspects of improvement, in order to provide some reference for the small and medium sized leisure food enterprises.
\end{abstract}

\section{Introduction}

Leisure food is also fast consumer goods, is in people's leisure, eat when the rest of the food. The most appropriate explanation is to eat the food. The main play classifications are: nuts, puffed food, candy, meat products etc. with the continuous development of China's national economy, people demand the diversification of consumption, leisure the trend was more obvious, the change of consumption and promote the development in our country leisure food industry, leisure food enterprises like bamboo shoots after a spring rain rise rapidly. According to official data Chinese brand network display in the well-known small and medium-sized brand casual snacks as many as 900, registered in the China trademark registration department is as high as more than 10 in this increasingly 10000. In the fierce competition, how to develop effective marketing strategies, effectively carry out marketing activities worthy of thinking for every small and medium leisure food enterprises.

\section{PEST Analysis of Small Leisure Food Enterprises}

Political Environment Analysis. Since the reform and opening up, China's economic level rising, on the one hand, and the corresponding food supervision has been strictly. In recent years people for food knowledge are constantly changing, according to the requirements of the majority of the people, reflected in the policy is the introduction of relevant laws and regulations and perfect. For example the relevant departments of the state transition, with net sales of food cross regional supervision idea, implementation of food supervision system of national coverage, but also the whole system of collaboration net sales for food supervision. And in the first half of 2016 issued "network of food safety violations investigated and implemented and measures on the October 1, 2016.

Economic Environment Analysis. According to eastmoney.com data show that GDP stability in our country, which in 2016 GDP was 6.7\%, which belongs to the high-speed growth. People brought in economic development potential demand for food consumption, provides an economic basis for the growth of GDP the demand change. At the same time, the development of market economy, bring is the people's disposable income increased. In improvement of people living standard, the hands of the increase in disposable income at the same time for the quality of life will have different requirements for people to eat also eat good enough to eat to eat healthy. 
Social Environment Analysis. Eating snacks has become a global boom and China's population, the development potential is large. According to Nielsen's survey data show that more than $90 \%$ Americans every day to eat snacks, of which $25 \%$ people every day to eat 3 to 5 times a year in Europe; snacks consumption close to $\$ 170$ billion; and the Asia Pacific region the annual consumption of $\$ 50$ billion. Small business is industrial snacks more than $\$ 400$ billion, and at an annual rate of $2 \%$. The steady growth of the leisure food industry will become the next ten years, the most promising gold industry. Finally, the health needs and help leisure food and health of the industry growth steadily, promote the upgrading of consumption industry boom.

Technology Level Analysis. With the development of information technology, the domestic scholars began to study on the mode of $\mathrm{O} 2 \mathrm{O}$ electronic commerce is more thorough, the analysis of the traditional business enterprise development present situation, discussed $\mathrm{O} 2 \mathrm{O}$ e-commerce profit model, to explore the way for the development of e-commerce business. At the same time, the progress of the times, the traditional technique gradually replaced by modern science. It provides support for the sale of goods, do not have to worry about inventory shortage. In the progress of modern technology is also reflected in the number of leisure food is increasing, people have found that the number of new products at the same time also has the ability to be far from around the world gathered in food at the same time delivery point to ensure product freshness and qualified rate.

\section{Analysis of the Marketing Problems of Small Leisure Food Enterprises}

Product Positioning is not Clear, the Serious Homogenization Phenomenon. More competitive in leisure food develops very quickly in recent years, due to the entry threshold is not high, a lot of money flowing into the snack food industry, which has also intensified the competition. Because the technology industry is not high and the lack of innovation, homogenization and leisure food the more serious, not only a lot of brand packaging, style and color similarity is very high, the taste is the same. At the same time, many small and medium-sized leisure food enterprises do not have the advantage in the brand, it is difficult to attract consumer attention.

The Use of Low Price Competition, Product Quality is Ignored. In the same product of similar circumstances, small and medium-sized enterprises only take all kinds of leisure food marketing and sales, promotions and frequent, the price war is the most commonly used method, it will inevitably promote the leisure food enterprises more competitive, leading enterprises to survive the pressure increases. In the fierce price competition at the same time, food safety has become a easily overlooked problem, some enterprises in order to pursue even temporary interests, the processing of raw materials used does not comply with national health standards.

The Circulation Channel is Unitary, the Integration Degree is not High. The current leisure food sales are mainly large supermarket sales in the supermarket group, scattered into individual leisure food, grocery sales, Internet sales. A large supermarket is undoubtedly the main pin and leisure food enterprises compete for sales channels, the visibility and credibility of ascension product sales of large supermarket own large supermarket shelves, however expensive costs and stringent threshold will into the store, many small and medium-sized businesses and leisure food sales network. Because customers see leisure food itself, the lack of experience of certain, therefore will be part of customers away.

Lack of Market Operation Capability. Small snacks enterprise strength is limited, relative to competitors, the channel control ability inevitable disadvantage, and channels of bargaining chips; at the same time, the lack of marketing talent market, the lack of operational experience, marketing methods, activate the market capacity is limited; restricted financial strength is stretched in advertising publicity, not to big celebrity endorsements, unable to buy advertising time high ratings of television and so on, these are made of small leisure food enterprises lose the advantage in the competition. 


\section{P Marketing Strategy of Small Leisure Food Enterprises}

Terms of Product. First, accurate market positioning requires companies to further understand the needs of consumers to provide quality products. In recent years, leisure food to a low calorie, low fat, low sugar nutritious healthy development. Enterprises regard customer's demand as the starting point for health and Nutrition Research Institute was established, to help consumers nutrient absorption perspective of product collocation, to meet customer needs. For example, leisure food enterprises, according to the human daily nutrition needs scientific and reasonable collocation of nuts, and directly in the package when they meet the health standards of food packaging, and eat a packet can indicate to meet the needs of today. Secondly, the quality of product quality requirements for quality, achieve strict supervision. In the selling process, the first step to a good start, we need the high quality of enterprise products, so as to attract consumers The enterprise to buy your favorite goods. For leisure food, taste and quality are still in the first place. Product safety and freshness is undoubtedly the customer concerned. This requires the enterprise social responsibility from the food source to control, the choice of quality suppliers, and strict delivery standards. The strict checks request until it is delivered to the hands of consumers, to ensure food safety and freshness. Finally, rich product category, to meet the different needs. In recent years, leisure food brand to enhance the product quality to high-end development. Small and medium-sized enterprises can collect zero leisure food raw materials imported from around the world for food processing, while improving product grade can meet the diverse needs of consumers.

Terms of Price. Reasonable price can let the enterprise in profit at the same time to cultivate customer loyalty to the brand. For the products of small and medium enterprises need to combine their own leisure snacks market positioning, accurate pricing methods, comprehensive use of various pricing strategies to achieve economic goals. Most of the leisure food enterprises to choose the low price competition, and the loss of a portion of the profits, but also easily lead to a vicious price war not necessary. Today, consumer leisure food gradually extended to more people, the market is further broken down, the young fashion youth group is still the mainstream leisure food consumption. For young customers love to try new things, is not sensitive to the price of consumer psychology, can start from product differentiation, enhance the core product price, take off fat pricing, to meet customer needs and achieve the sales of early adopters, profit growth. If bundling is now leisure food enterprises to increase sales One way to give appropriate preferential pricing of product portfolio will attract consumers to buy the suite. So for leisure food, after careful product portfolio sales to consumers of nutrition collocation, combination of the most reasonable collocation can also improve profitability.

Terms of Channel. At present, the fierce market competition, many enterprises constantly enter the leisure food industry, consumers have more choice, but also made more for higher requirements. And with the development of information technology and network technology, the traditional line marketing segment has been unable to meet the development of the leisure food industry demand. Especially in everyone generally choose online shopping today, too much attention under the line of marketing is to give up a large part of the consumer groups. Mode of future sales of goods is to business platform, creating a new consumer scene to replace the platform becomes a bridge between businesses and consumers. In the process of traditional marketing in some elements will become a key factor in business transactions in the future. In the aspect of marketing channel innovation, small and medium-sized enterprises should have more leisure snacks is innovative The channel marketing ideas. First, through the 020 business model, realize the integration of online and offline, stores, commodity supply chain and business organically, to ensure that consumers can more channels in the actual experience of quality products at the same time to buy goods. Secondly, to carry out a full channel marketing strategy. Multiple thinking, full channel marketing, leisure food enterprises can use local social life channel, the electricity supplier, third party business platform and self APP multiple channels to carry out a comprehensive marketing. The last is managed by the entity shop franchise. Physical stores to enhance consumer products at the same time on intuitive feelings, enhance brand awareness. 
Terms of Sales Promotion. Leisure food enterprises should keep pace with the times to achieve modernization promotion. The integration of online communication channels in $\mathrm{O} 2 \mathrm{O}$ mode driven around the same goal, communication information of product line under the full range of publicity. Such as through WeChat, micro-blog push marketing messages and collect customer feedback, promote two-way interactive communication with consumers, encourage the line experience. At the same time, the traditional promotion at the same time, join the video propaganda. There are many kinds of all kinds of advertising, the advertising boom hit sometimes can not reach the minds of consumers, can only be regarded as vulgar advertisement. At the same time, restricted by the financial strength of the small and medium-sized enterprises, leisure food advertising budget is limited, there is no big star endorsement unable to buy advertising time, high ratings of television and so on, these are made of small leisure food enterprises can not compete with the industry leader. When the television drama propaganda The way has become a good choice. In the movie ads, for leisure food enterprises have been very common. In the process we see light television drama, seamless advertising not only let us remember the enterprises and products, while participating in the star has formed a kind of invisible propaganda and leading role. Another example of micro film marketing and some network Reds cooperation network broadcast platform promotion. The promotion for the advertising budget tight small snacks business is a good choice. Micro film marketing is a kind of social communication mode through self media platform, is a new network between commercial films and general video marketing means. The biggest difference with the traditional film implanted marketing micro film, it is better than traditional stiff advertising implant is more gentle, the enterprise can be expressed The information is integrated into the narrative style of the story itself so that the audience can accept and propagate the brand in the invisible

\section{Conclusion}

The changes of the times, regardless of how to change people's way of life can not leave the basic necessities of life in these aspects, in this classification, the "food" in the new show: leisure food in people's lives gradually become an indispensable market. Bring leisure food enterprises more and more opportunities, at the same time, any leisure food companies should clearly recognize that the leisure food is not to meet the basic needs of consumers this "full" intention. Facing the market demand, in the face of competition for leisure food industry in small and medium enterprises, we must first find their own problems, and through increased product development efforts to improve the quality of products, integration of sales channels a full range of positive publicity to activate the market competitiveness and enhance the recognition of its business and products. Only take the appropriate marketing strategy, and Hugh The leisure food enterprises to seize the market opportunities, and survived to become the industry leader in the fierce market competition towel.

\section{Acknowledgements}

Research Project of Yulin science and technology: " Research on regional brand marketing model of Yulin red dates based on Industrial Cluster "(2015CXY-13-04)

\section{References}

[1] Sun Ling. Big data for small snacks[J].IT Manager World, 2016, (10)

[2] Shi Yajuan. Nice shop, reverse O2O, fun online, offline [J]. Chinese and Foreign Management, 2016, (05)

[3] Yang Lili The marketing strategy of Ningxia houshengji Food Co [D]. Yinchuan: Ningxia University, 2014.

[4] Zhang Yibing, Liang Jieqin. The personification of marketing strategy of leisure food brand [J]. News Herald, 2016, (19).

[5] Bo lina. Study on Strategy of developing micro film marketing in snack food industry [J]. Modern Economic Information, 2015 (23) 